\title{
An Elasto-viscoplastic Model for Soft Clay
}

\author{
Z.Y. Yin ${ }^{1,2}$, P.Y. Hicher ${ }^{1}$, Y. Riou ${ }^{1}$, H.W. Huang ${ }^{2}$
}

\begin{abstract}
The purpose of this paper is to present the development of an elasto-viscoplastic model for normally consolidated clay. A three dimensional constitutive equation was derived based on the framework of Perzyna's overstress theory and Modified CamClay model. It was implemented in a finite element program, and applied to analyze time-dependent behavior of soft clay. The influence of two viscous parameters, which can be determined by undrained triaxial compression tests, was studied. The proposed model was verified using observed laboratory responses of several natural clays. The results showed that the model can satisfactorily describe the stress-strainrate behavior such as strain rate effect, creep and stress relaxation.
\end{abstract}

\section{Key words}

Elasto-viscoplastic, finite element, overstress, Cam-Clay, time-dependent

\section{Introduction}

Several models integrating the viscous behavior of fine soils have been proposed in the literature (for example, Adachi and Oka 1982, Hinchberger 1996, Fodil et al. 1997, Zhang 2003), but not widely used in geotechnical engineering. The purpose of this study is to develop a viscoplastic model simple enough to be easily calibrated and used in geotechnical projects.

This present paper has three objectives in studying the viscoplastic behavior of clay : (i) to deduce constitutive equations and implement them in a finite element program; (ii) to study the influence of the viscous parameters; (iii) to explore the implications of modeling the time-dependent behavior of natural clays.

\footnotetext{
${ }^{1}$ Institut de Recherche en Génie Civil et Mécanique, GeM UMR CNRS 6183, Ecole Centrale de Nantes, BP 92101, 44321 Nantes Cédex 3, France ; Tel : 0033-240371666 ; Email : zhenyu.yin@ec-nantes.fr

${ }^{2}$ Department of Geotechnical Engineering, Tongji University, 1239 Siping Road, Shanghai 200092, PR China;

Tel : 0086-21-65982986 ; Email: huanghw@mail.tongji.edu.cn
} 


\section{Elasto-viscoplastic Modified Cam-Clay model}

The Modified Cam-Clay model was proposed by Roscoe and Burland in 1968 and has been widely used for estimating time-independent behavior of soft clay. Formulations of this model are suitable for use in finite element analysis. For these reasons, the Modified Cam-Clay model was adopted as a basis for the formulation of a viscoplastic model.

Constitutive equations of the viscoplastic model. According to the work of Adachi and Oka 1982, we define a static yield criterion " $f_{s}$ " which represents a reference yield surface for the material. Its initial shape depends on the consolidation pressure " $p_{c}$ ". The expansion of the static yield surface, which describes the hardening of the material, is expressed by the variation of the consolidation pressure due to the inelastic volumetric strain " $\varepsilon_{v}{ }^{v p "}$ :

$$
\partial p_{c}^{s}=p_{c}^{s} \cdot \frac{1+e_{0}}{\lambda-\kappa} \cdot \partial \varepsilon_{v}^{v p} \text { or } p_{c}^{s}=p_{c 0} \cdot \exp \left(\frac{1+e_{0}}{\lambda-\kappa} \varepsilon_{v}^{v p}\right)
$$

A dynamic yield criterion " $f d$ " is defined to represent the current state of stress and is expressed as follows.

$$
f_{d}=\frac{q^{2}}{M^{2}}+p^{\prime} \cdot\left(p^{\prime}-p_{c}^{d}\right)=0
$$

Based on " $p_{c} s$ " and " $p_{c}{ }^{d "}$ ", the scaling function " $\mu \Phi(\mathrm{F})$ ", which controls the amplitude of the viscoplastic strain rate, is taken as the power form or exponential form as follows.

$$
\mu \cdot \phi(F)=\mu \cdot\left(\frac{p_{c}^{d}}{p_{c}^{s}}-1\right)^{N} \text { or } \mu \cdot \phi(F)=\mu \cdot\left(\exp \left[N \cdot\left(\frac{p_{c}^{d}}{p_{c}^{s}}-1\right)\right]-1\right)
$$

where, " $\mu$ " and " $N$ " are the viscous parameters of this model. The flow rule for the viscoplastic strain rate in a simple case of infinitesimal strain field follows the form proposed by Perzyna 1966:

$$
\dot{\varepsilon}_{i j}^{v p}=\mu\langle\phi(F)\rangle \frac{\partial f_{d}}{\partial \sigma_{i j}^{\prime}}
$$

where, the function of MacCauley is expressed as: $\langle F\rangle=\left\{\begin{array}{l}0 \cdot \text { for } \cdot F \leq 0 \\ F \cdot \text { for } \cdot F>0\end{array}\right.$. The principle of the viscoplastic model is presented in Figure 1. Taking into account the elastic stress-strain relations, constitutive equations of this viscoplastic model for normally consolidated clays are derived as follows:

$$
\dot{\varepsilon}_{i j}=\frac{\dot{s}_{i j}^{\prime}}{2 G}+\frac{\dot{p}^{\prime}}{3 K}+\mu\langle\phi(F)\rangle\left(\frac{3 s_{i j}^{\prime}}{M^{2}}+\left(2 p^{\prime}-p_{c}^{d}\right) \frac{\delta_{i j}}{3}\right)
$$




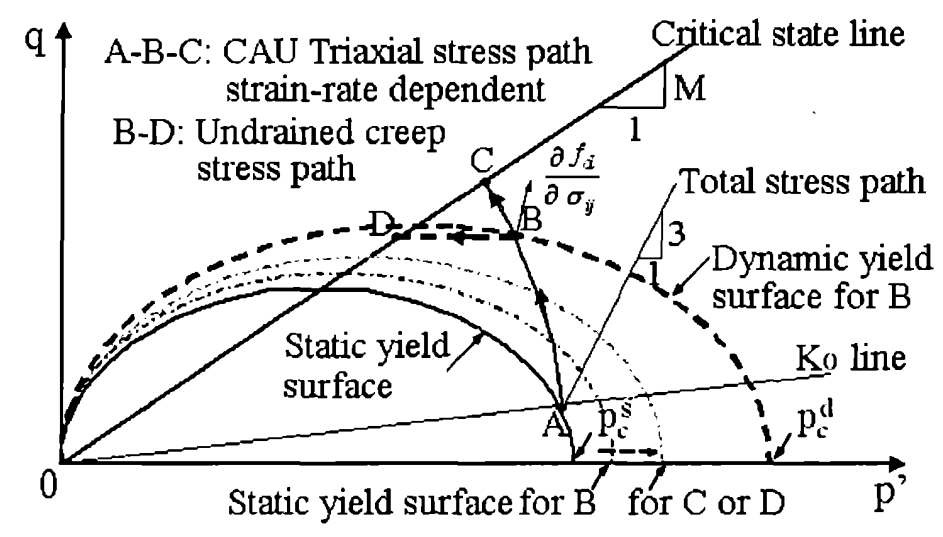

Figure 1. Schematic behavior of the elasto-viscoplastic Modified Cam-Clay model during CAU triaxial compression and triaxial creep tests.

Finite element analysis. The basic finite element scheme with an elasto-viscoplastic model is similar to those presented by Oka and Adachi 1986 and Hinchberger 1996. At time $t_{n}$, for the time steps $d t_{n}=t_{n}-t_{n-1}$, the viscoplastic strain increment using Euler numerical constant " $\theta=1$ " can be written as follows:

$$
\left[\Delta \varepsilon^{v p}\right]_{n}=\Delta t_{n} \cdot\left[\dot{\varepsilon}^{v p}\right]_{n}
$$

The stress increment vector can be written as follows:

$$
\left[\Delta \sigma^{\prime}\right]_{n}=\left[D^{e}\right] \cdot\left([\Delta \varepsilon]_{n}-\Delta t_{n} \cdot\left[\dot{\varepsilon}^{v p}\right]_{n}\right)
$$

We have the equations of nodal displacements and nodal loads:

$$
[\Delta \varepsilon]_{n}=[B]_{n} \cdot[\Delta d]_{n}, \quad[\Delta F]_{n}=\int_{V}[B]_{n}^{T} \cdot\left[\Delta \sigma^{\prime}\right]_{n} \cdot d V
$$

The incremental form of the finite element equation is written as:

$$
\left.\left.[\Delta F]_{n}=\int_{V} B\right]_{n}^{T} \cdot\left(\left[D^{e}\right] \cdot\left([B]_{n} \cdot[\Delta d]_{n}-\Delta_{n} \cdot\left[\dot{\varepsilon}^{v^{p}}\right]_{n}\right)\right) \cdot d V=[K]_{n} \cdot[\Delta d]_{n}-\int_{V} B\right]_{n}^{T} \cdot\left[D^{e}\right] \cdot \Delta_{n} \cdot\left[\dot{\varepsilon}^{\nu p}\right]_{n} \cdot d V
$$

Once the increments of stresses and strains are calculated, the results can be obtained at time $t_{n}$ :

$$
\left[\sigma^{\prime}\right]_{n}=\left[\sigma^{\prime}\right]_{n-1}+\left[\Delta \sigma^{\prime}\right]_{n} \quad[d]_{n}=[d]_{n-1}+[\Delta d]_{n} \quad\left[\varepsilon^{v p}\right]_{n}=\left[\varepsilon^{v p}\right]_{n-1}+\left[\Delta \varepsilon^{v p}\right]_{n}
$$

For a coupled consolidation analysis based on Biot theory, the relationship of the load increment is given by applying the principle of virtual work to the equilibrium equation as shown by Oka and Adachi 1986:

$$
\left.\left.\left.\left.\int_{V}[\Delta \varepsilon]^{T} \cdot[\Delta \sigma] \cdot d V=\int_{V} \Delta \varepsilon\right]^{T} \cdot\left[\Delta \sigma^{\prime}\right] \cdot d V+\int_{V} \Delta \varepsilon\right]^{T} \cdot\left[\Delta u_{w}\right] \cdot d V=\int_{V} \Delta \Delta d\right]^{T} \cdot\left[\Delta F_{b}\right] \cdot d V+\int_{S} \Delta d\right]^{T} \cdot[\Delta T] \cdot d S
$$

The detailed information of coupled consolidation analysis can be found in Zienkiewicz and Taylor 1989. 


\section{Scaling function study}

In viscoplastic models for soils, two types of scaling function are usually proposed: a power form and an exponential form (Eq.3). The test results show that the stress evolution for a given deformation is rather proportional to the logarithmic strain rate. The model responses for these two types of scaling functions were carried out on undrained triaxial compression tests at different strain rates. The Modified Cam-Clay model parameters proposed by Vaid and Campanella 1977 were taken (Table 1a), and the values of " $N$ " varied from 1 to 20 . For each value of " $N$ ", we determined " $\mu$ ", in order to obtain the same maximum stress value at a strain rate of $10 \% / \mathrm{min}$. The results are presented in Figure 2. One can see that the exponential type scaling function allows to limit the increase of $\mathrm{q}$ with the strain rate and therefore enlarges the domain of application of the viscoplastic model, as pointed out by Fodil et al. 1997. Thus, the exponential type relation was considered in the following study.

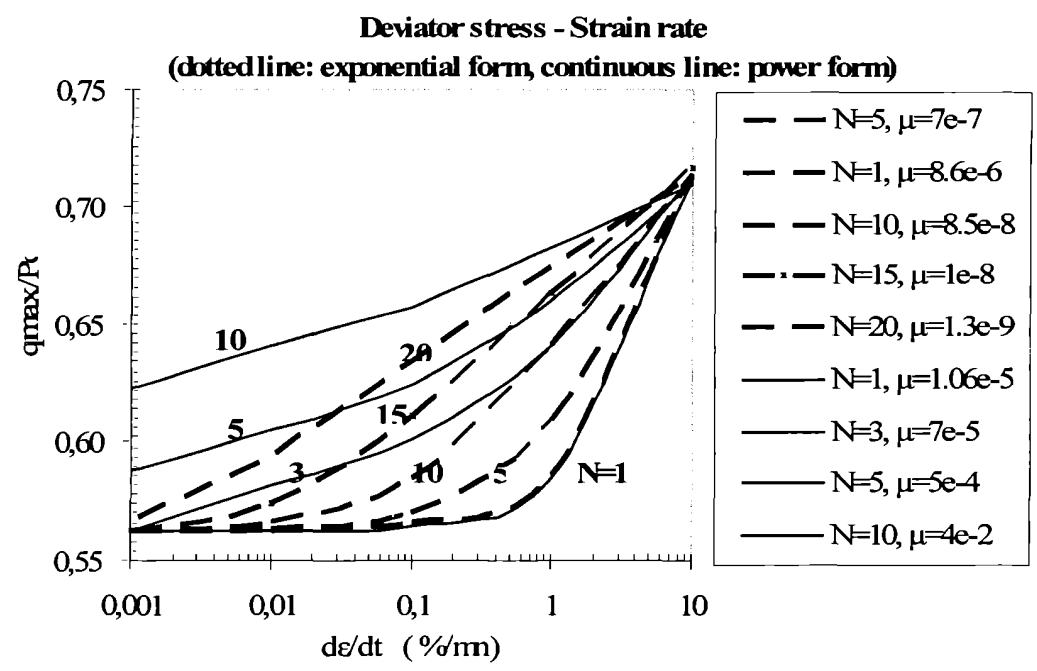

Figure 2. Comparison of exponential and power type scaling function

\section{Parameters study}

The elasto-viscoplastic model comprises seven parameters which include:

- mechanical parameters which can be determined by triaxial compression test, i.e., Young's modulus "E", Poisson's ratio "v", slope of the critical state line "M";

- mechanical parameters which can be determined by oedometer test and density test, i.e., preconsolidation pressure " $p_{c 0}$ ", compressibility index " $(\lambda$ $\kappa) /\left(1+e_{0}\right) "$, where $\lambda$ is the compression index, $\kappa$ is the swelling index, $e_{0}$ is void ratio;

- viscous parameters which can be determined by specific tests such as creep test, relaxation test and strain rate test, i.e., " $\mu$ " and " $N$ ".

In this study, the particular attention was paid on the influence of the viscous parameters. Undrained triaxial compression constant strain rate tests were carried out for studying the influence of the viscous parameters: the values of the Cam-Clay parameters proposed by Rangeard 2002 for Saint-Herblain Clay were considered in this example (Table 1b). The numerical simulations are presented in Figure 3. The main conclusions are the following: 
- The maximum deviatoric stress decreases when the value of " $N$ " is increased. The influence on $q_{\max }$ is greater for small " $\mathrm{N}$ " values and becomes less pronounced when $N>30$. A smaller " $N$ " represents a larger viscosity.

- The maximum deviatoric stress increases by increasing the " $\mu$ " value. For small values of " $\mu$ " $\left(\mu<10^{-5}\right), q_{\max }$ reached a constant minimal value. While high values of " $\mu$ ", an almost linear relationship between $q_{\max }$ and $\log (\mu)$ was obtained. A smaller " $\mu$ " represents a larger viscosity.

- The relationship between $q_{\max }$ and the logarithm of the strain rate is almost linear. It is influenced in a different way by " $N$ " and " $\mu$ ": the slope depends on " $N$ ", but not on " $\mu$ ". This will allow us to determine firstly the " $N$ " value according to the slope of the "deviatoric stress - strain rate" curve, and then to determine " $\mu$ " according to the value of the deviatoric stress.

(a) Deviatoric stress - strain

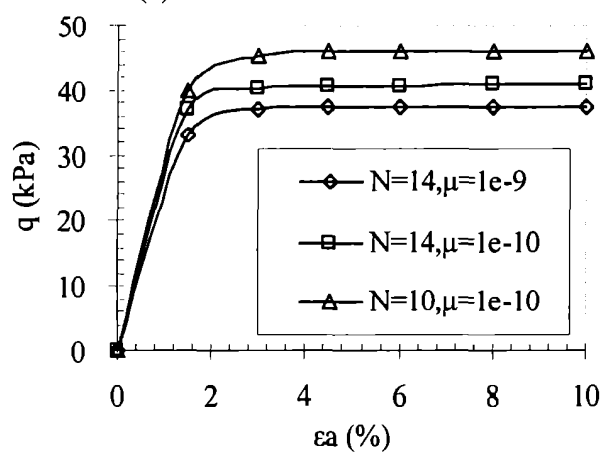

(c) Maximum deviatoric stress - $\mathrm{N}$

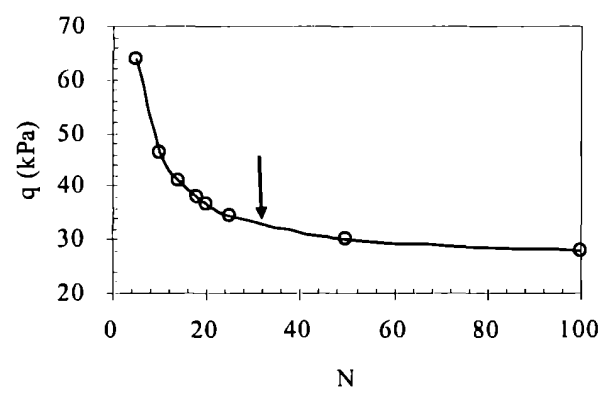

(b) Maximum deviatoric stress - strain rate

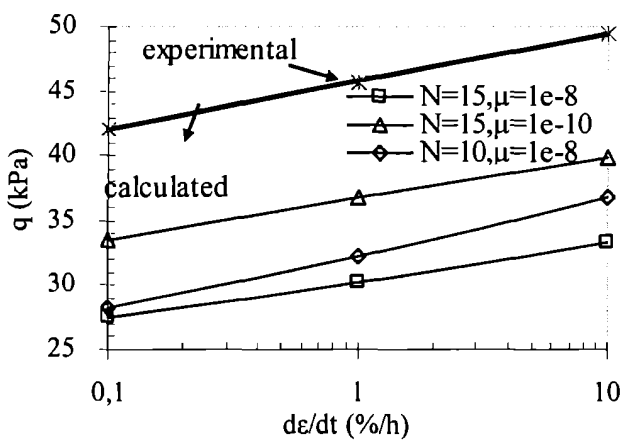

(d) Maximum deviatoric stress $-\mu$

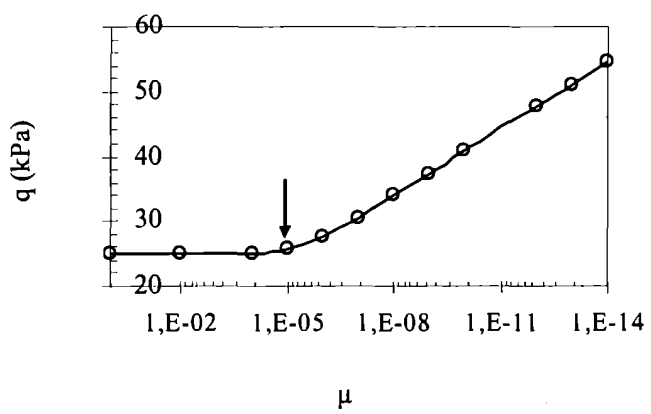

Figure 3. Influence of viscous parameters " $N$ " and " $\mu$ " at strain rate test

\section{Numerical simulation}

Simulation of triaxial test. Undrained triaxial constant strain rate tests on Haney clay were reported by Vaid and Campanella 1977. The samples were initially consolidated under an effective isotropic confining pressure of $515 \mathrm{kPa}$ for 36 hours and then were allowed to stand for 12 hours under undrained conditions before starting the shearing test. The material parameters are summarized in Table 1a. Numerical simulations show a good agreement between measured and predicted results (Fig. 4.).

Results of stress-relaxation tests on the Flumet clay were provided by Fodil et al.1997. An axial strain rate of $0.15 \% / \mathrm{h}$ was applied. The stress-relaxation tests were performed on the same sample for each test at about $1 \%, 3.5 \%$ and $6.7 \%$ of axial strain and lasted at least $24 \mathrm{~h}$. The parameters are summarized in Table 1(c). The viscoplastic model predicts reasonably well the results of the stress-relaxation tests, as shown in Figure 5. 
Anisotropically consolidated undrained triaxial compression tests (CAU) on Sackville clay provided by Hinchberger 1996 were also simulated. The axial strain rates ranged from $0.009 \% / \mathrm{min}$ to $1.14 \% / \mathrm{min}$. In addition, CAU triaxial creep tests were performed at deviatoric stresses from $35 \mathrm{kPa}$ to $50 \mathrm{kPa}$ after an initial anisotropic consolidation for 24 hours. The parameters used in the analysis are summarized in Table 1(d). A good agreement between measured and calculated responses was obtained (Fig. 6).
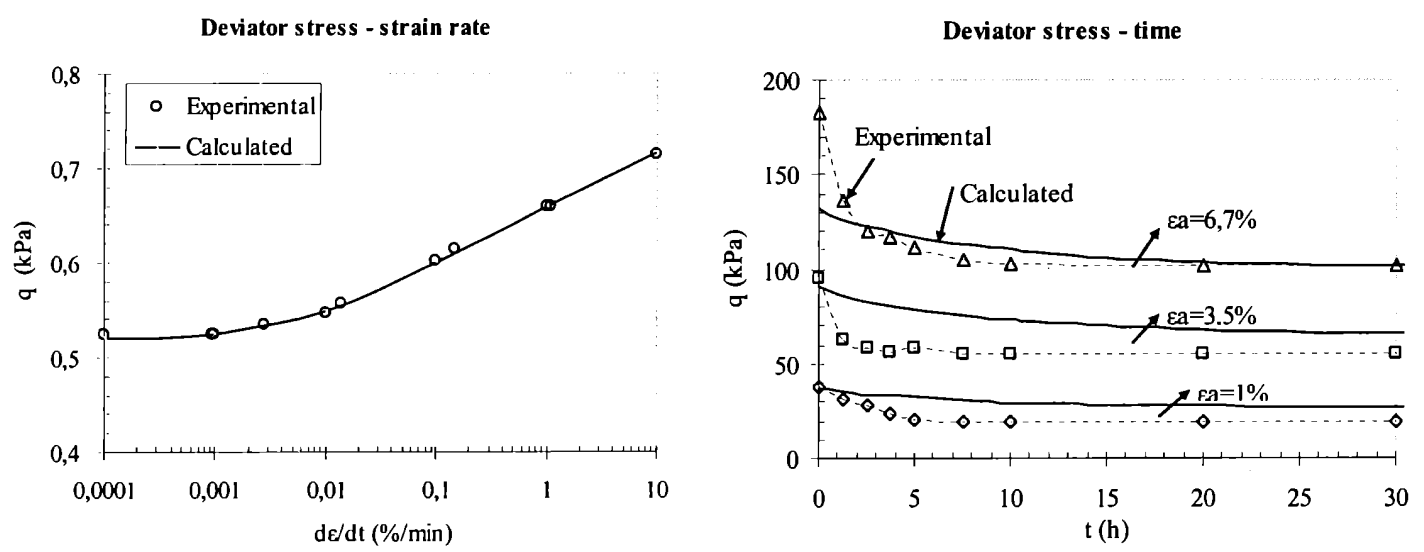

Figure 4. Strain rate test on Haney clay Figure 5. Relaxation test on Flumet clay

(a) Deviator stress - strain

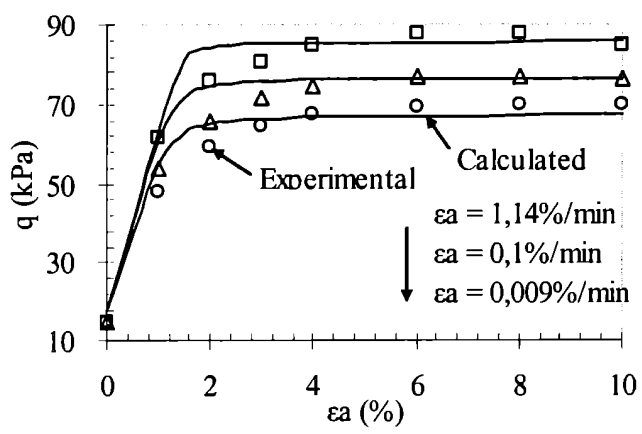

(c) Strain - time for creep test

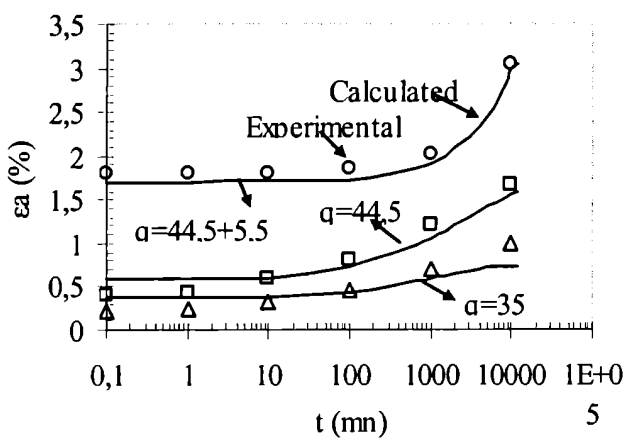

(b) Deviator stress - strain rate

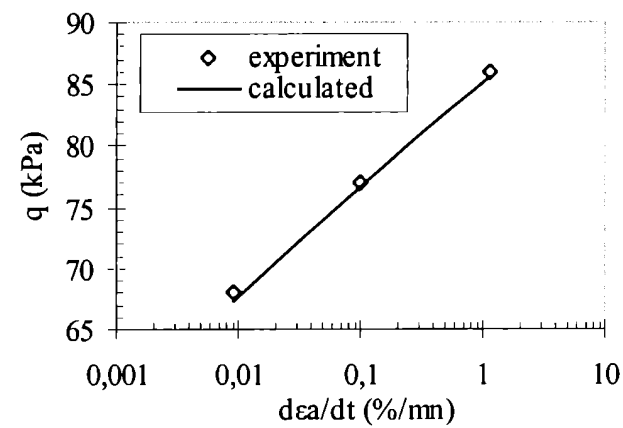

(d) excess pore pressure - time

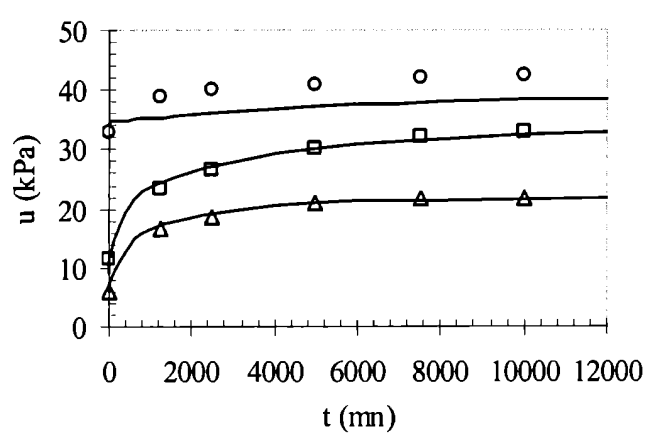

Figure 6. Strain rate and creep tests on Sackville clay

Simulation of long term oedometer test. Long term 1D consolidation test results were provided by Hinchberger 1996 on Sackville Clay. Drainage was allowed at top and bottom of a $2.0 \mathrm{~cm}$ thick specimen. A permeability value " $\mathrm{k}=1.5 \times 10^{-8} \mathrm{~m} / \mathrm{min}$ " was given by Hinchberger. Fig. 7 presents the comparison of measured and predicted results for a vertical loading increment from $50 \mathrm{kPa}$ to $100 \mathrm{kPa}$. The material parameters are summarized in Table le. 
Fig. 8 presents results obtained on Gloucester Clay (Lo et al.1976). The height of the specimen was $2.0 \mathrm{~cm}$. One-way drainage was allowed during the consolidation and the permeability " $\mathrm{k}$ " was equal to $7.2 \times 10^{-8} \mathrm{~m} / \mathrm{min}$.

These results show that the viscoplastic model is capable of calculating with good accuracy the long term settlement of natural clay.

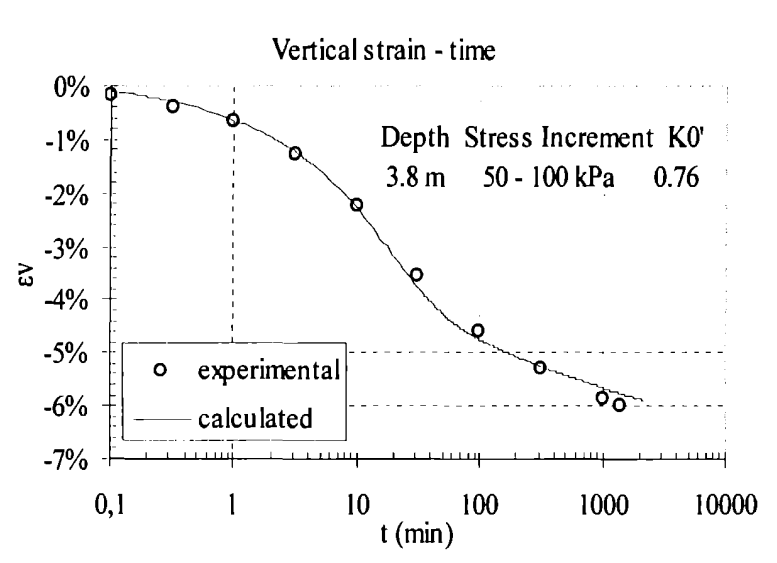

Figure 7. 1D test on Sackville clay

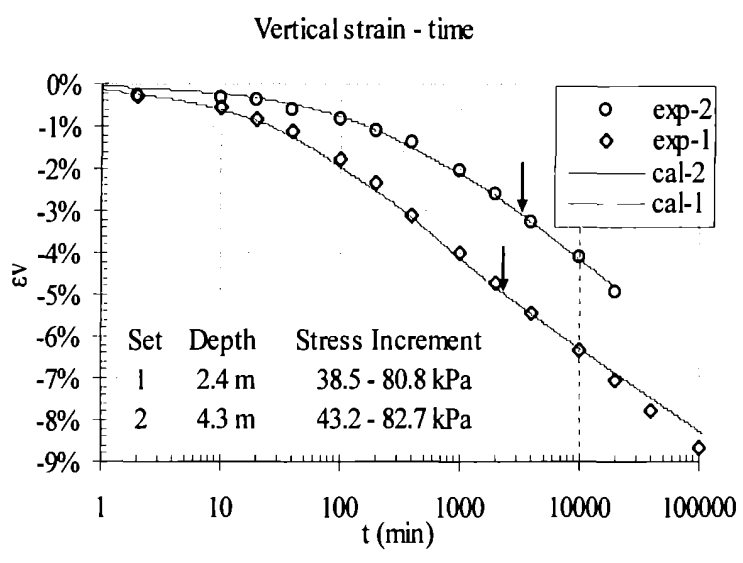

Figure 8. 1D test on Gloucester clay

Table 1. Summary of constitutive parameters

\begin{tabular}{cccccccccc}
\hline $\mathrm{N}^{\circ}$ & $\begin{array}{c}\mathrm{E} \\
(\mathrm{kPa})\end{array}$ & $v$ & $\lambda$ & $\mathrm{K}$ & $\mathrm{M}$ & $\mathrm{e}_{0}$ & $\begin{array}{c}\mathrm{P}_{\mathrm{c} 0}^{\prime} \\
(\mathrm{kPa})\end{array}$ & $\mathrm{N}$ & $\begin{array}{c}\mu \\
(1 / \mathrm{s} . \mathrm{kPa})\end{array}$ \\
\hline $1(\mathrm{a})$ & 35000 & 0.25 & 0.315 & 0.048 & 0.85 & 2 & 515 & 12.5 & $3.3 \mathrm{E}-9$ \\
$1(\mathrm{~b})$ & 2340 & 0.3 & 1.22 & 0.07 & 1.2 & 4 & 40 & 12 & $2.6 \mathrm{E}-12$ \\
$1(\mathrm{c})$ & 4000 & 0.3 & 0.174 & 0.024 & 1.5 & 1.28 & 70 & 10 & $1.0 \mathrm{E}-8$ \\
$1(\mathrm{~d})$ & 4000 & 0.3 & 0.28 & 0.06 & 1.49 & 1.14 & 53 & 8.0 & $7.0 \mathrm{E}-10$ \\
$1(\mathrm{e})$ & 3000 & 0,3 & 0,23 & 0,04 & 1,39 & 1,25 & 30 & 10 & $7.0 \mathrm{E}-10$ \\
$1(\mathrm{f})$ & 1300 & 0,3 & 0,65 & 0,025 & 1.0 & 1,8 & 40 & 10 & $1,0 \mathrm{E}-11$ \\
$1(\mathrm{f})$ & 1500 & 0,3 & 0,65 & 0,025 & 1.0 & 1,8 & 46 & 10 & $1,0 \mathrm{E}-11$ \\
\hline
\end{tabular}

In summary, the constitutive equations based on Modified Cam-Clay model and overstress theory were evaluated in the present study and found to satisfactorily describe the time-dependent behavior of several natural clays, isotropically and anisotropically consolidated, under various stress-strain-time loadings.

\section{Conclusions}

An elasto-viscoplastic model developed to describe the time-dependent behavior of normally consolidated soft clay was presented in this paper. The constitutive equations were based on Modified Cam-Clay elastoplastic model and Perzyna's overstress viscoplastic theory. The exponential type scaling function was adopted to enlarge the domain of application of this model.

The model has seven parameters, 5 describing the elastoplastic behavior, which can be determined directly from laboratory tests such as triaxial tests and oedometer tests, 2 describing the viscous behavior, which can be determined by curve fitting.

The proposed model was employed to predict a number of undrained triaxial tests and long-term oedometer tests on several isotropically and anisotropically consolidated clays: Saint-Herblain clay, Haney clay, Flumet clay, Sackville clay and Gloucester clay. Good agreement between measured and predicted results was 
achieved for different loading conditions: constant strain rate tests, stress-relaxation tests and creep tests.

The predictive capability of this model needs further validation, such as the prediction of infrastructures built on soft clay.

\section{Acknowledgements}

The research reported in this paper is funded by a grant from "Conseil Regional des pays de la Loire".

\section{References}

Adachi, T. \& Oka, F. (1982). Constitutive equations for normally consolidated clay based on elasto-viscoplasticity. Soils and Foundations, 22(4), Dec, p57-70.

Fodil, A., Aloulou, W. \& Hicher, P.Y. (1997). Viscoplastic behaviour of soft clay. Geotechnique, 47(3), Aug, p 581-591.

Hinchberger S. D. (1996). The behaviour of reinforced and unreinforced embankments on rate sensitive clayey foundations. Thesis at University of Western Ontario, Canada.

Lo, K. Y., Bozozuk, M. \& Law, K. T. (1976). Settlement analysis of the Gloucester test fill. Canadian Geotechnical Journal, 13(4), Nov, p 339-354.

Oka, F., Adachi, T. \& Okano, Y. (1986). Two-dimensional consolidation analysis using an elasto viscoplastic constitutive equation. International Journal for Numerical and Analytical Methods in Geomechanics, 10(1), Jan-Feb, p 1-16.

Perzyna P. (1966). Fundamental problems in viscoplasticity. Advances in Applied Mechanics, volume 9, pp. 243-377 Academic Press.

Rangeard D. (2002). Identification des caractéristiques hydro-mécaniques d'une argile par analyse inverse des essais pressiométriques. Thèse de l'Ecole Centrale de Nantes et l'Université de Nantes.

Roscoe, K.H. \& Burland, J.B. (1968). On the Generalized Stress-Strain Behavior of Wet Clay. Engineering Plasticity, p 535-609.

Vaid, Y.P. \& Campanella, R.G.. (1977). Time-dependent behavior of undisturbed clay. American Society of Civil Engineers, Journal of the Geotechnical Engineering Division, 103(7), Jul, p 693-709.

Zienkiewicz, O.C. \& Taylor, R.L. (1989). The finite element method. $4^{\text {th }}$ ed. McGraw-Hill, London.

Zhang D. (2003). Analysis of time-dependent behavior of soft clay and its application on the prediction of long-term settlements of tunnels. Thèse de l'Ecole Centrale de Nantes et l'Université de Tongji (in chinese). 